\title{
Unpacking the "Black Box": Understanding the Effect of Social Network Characteristics on Safety Behaviors of Construction Workers
}

\author{
Shuquan Li, ${ }^{1}$ Pei Yang, ${ }^{1,2}$ Xiuyu Wu, ${ }^{1}$ Ge Wang $\mathbb{D}^{3,4}$ and Meng Fan ${ }^{5}$ \\ ${ }^{1}$ School of Management Science and Engineering, Tianjin University of Finance and Economics, Tianjin 300222, China \\ ${ }^{2}$ Department of Business Administration, Tianjin University of Commerce Boustead College, Tianjin 300384, China \\ ${ }^{3}$ College of Public Administration, Huazhong Agricultural University, 1 Shizishan Street, Wuhan 430070, China \\ ${ }^{4}$ Antai College of Economics and Management, Shanghai Jiao Tong University, Shanghai 200030, China \\ ${ }^{5}$ School of Economics and Management, Tianjin Chengjian University, Tianjin 300384, China \\ Correspondence should be addressed to Ge Wang; ge.wang@mail.hzau.edu.cn
}

Received 9 August 2020; Revised 25 October 2020; Accepted 26 October 2020; Published 18 November 2020

Academic Editor: Xianbo Zhao

Copyright (c) 2020 Shuquan Li et al. This is an open access article distributed under the Creative Commons Attribution License, which permits unrestricted use, distribution, and reproduction in any medium, provided the original work is properly cited.

\begin{abstract}
How to improve the safety behaviors of construction workers has dogged the realm of construction project management. Previous studies mainly focused on the individual and/or organizational factors shaping safety behaviors, while there is a dearth of research focusing on the effect of individual-organizational nexus (i.e., the network embeddedness of individuals within the organization). Thus, this study employs social network analysis (SNA) and multivariable regression analyses to explore the relationship between the characteristics of social networks of construction workers (i.e., degree, closeness, and betweenness centralities) and their safety behaviors (i.e., safety participation and safety compliance), considering the mediating role of safety communication. The primary data were collected from ten Chinese construction projects. The results include the following three aspects. First, degree centrality, closeness centrality, and betweenness centrality all exert significant positive effects on safety participation. Closeness centrality yields a positive effect on safety compliance in formal networks. Degree centrality has a positive effect on both safety compliance and safety participation, whereas the other two centrality characteristics exhibit no significant effect in informal networks. Second, in formal networks, safety communication plays a partial mediation role between closeness centrality and safety compliance and a full mediation role between degree and closeness centralities and safety participation. Third, in informal networks, safety communication plays a full mediation role between degree centrality and safety compliance and a partial mediation role between degree centrality and safety participation. This study provides new insights for construction project management in achieving improved safety performance via shaping the social network characteristics.
\end{abstract}

\section{Introduction}

In recent years, the numbers of construction safety accidents and casualties have remained relatively high and impede sustainable project delivery $[1,2]$, especially in developing countries such as China that is experiencing unprecedented levels of urbanization [3]. In this regard, the factors that are responsible for the unsafe behaviors of construction workers attract increasing attention. Currently, studies on the factors shaping the safety behavior of construction workers mainly concentrate on two aspects. Some focus on the effect of individual factors, such as individual physical characteristics, attitude, and psychological motivation [4-7]. Others focus on the effect of organizational factors, such as safety management, safety climate, and safety culture [8-10]. However, there is a dearth of research focusing on the effect of individual-organizational nexus (i.e., the network embeddedness of individuals within the organization). Social network analysis (SNA) is defined as the analysis of structural characteristics of a relationship network of individuals, which considers the relationship of the organizational structure and individual characteristics [11]. As 
such, SNA establishes a bridge exploring the effect of individual-organizational nexus.

Furthermore, construction is a complex process with multifarious production links, integrated participation of professional teams, and unstable construction sites [12]. The relationship between people forms social networks. A construction professional team can be seen as a social network, in which workers cooperate and communicate with each other in daily work and life. The people who are embedded in this network are shaped by the structural characteristics of social networks [13]. In other words, the relationship among people can influence their behavioral decision-makings $[14,15]$.

In recent years, the influence of the relationship on behavior and performance has attracted increasing research interests. In the field of construction safety behaviors, SNA has been adopted to explore the relationship between unsafe behaviors of construction workers and the propagation path between unsafe behaviors [16]. However, there are few studies on the impact of social networks on construction workers' safety behaviors, and no in-depth study has been conducted on which SNA characteristics can effectively improve workers' safety behaviors. It is notable that individual ideology is affected by others, while construction workers present an obvious group phenomenon, and individual behavior consciousness will be affected by the surrounding environment of social groups [17]. Therefore, the social network characteristics of construction workers are potentially important factors shaping individual safety behaviors. This study focuses on the relationship between centrality characteristics of social networks of construction workers (i.e., degree, closeness, and betweenness centralities) and workers' safety behaviors (i.e., safety participation and safety compliance). The results are expected to shed new light on the improvement mechanism of the safety behaviors of construction workers and provide targeted guidance for improving the team design of construction workers as well as the safety performance of projects.

\section{Literature Review and Hypothesis}

2.1. Safety Behavior. Safety behavior refers to the conduct that workers must strictly adopt during construction activities to comply with existing regulations [18]. The accident causation theory identifies unsafe human behaviors as the most important factor in the occurrence of accidents. Behavior analysis methods have been extensively applied in the studies of workplace safety performance, such as the behavior-based safety approach, which has stimulated interest in individual safety behaviors [19]. Safety behavior is not a one-dimensional concept; according to Marchand et al. [20], workers' safety behavior can be divided into two dimensions, including caution and initiative. Specifically, the former focuses on workers' compliance with safety rules or systems, whereas the latter focuses on workers' efforts to improve the level of safety and environment. On this basis, Neal et al. [21] introduced the concept of workers' safety behaviors from the perspective of performance and divided workers' safety behaviors into safety compliance and safety participation. Safety compliance mainly refers to workers' compliance with safety regulations or work safely, whereas safety participation mainly includes the actions taken by workers to help their colleagues and improve the environmental safety of the workplace. Furthermore, Hofmann et al. [22] analyzed active safety behaviors and introduced the concept of safety citizenship behaviors (including help, disclosure, and civic virtues).

The two-dimensional division of safety behaviors proposed by Neal et al. [21] has been widely applied in safety research $[7,23,24]$; therefore, this study divided the construction workers' safety behavior into safety compliance and safety participation. Safety compliance refers to the compliance of construction workers with laws, safety regulations, and safety instructions concerning construction safety; and safety participation refers to the help and suggestions provided by construction workers during the construction process as well as their efforts to improve safety levels on the construction site.

2.2. Social Network. The social network is the social relations between a specific group. Scott [25] defined social networks as relatively stable systems of social relationships among certain individuals. Social networks reflect the interaction among members within an organization. According to Zenger et al. [26], organizations can be divided into formal and informal ones. Therefore, the social networks, formed by the interaction among members within an organization, can be divided into formal network and informal network, accordingly $[25,27]$. The formal network represents involuntary relationships that must be maintained to perform interdependent work within the organization (i.e., working network); and the informal network represents voluntary relationships that are formed independently in daily life, without the need to comply with any working rules (i.e., living network) [28]. Formal and informal networks coexist in organizations and play different roles with respect to workplace behaviors. Construction activities are featured by a relatively high level of autonomy. It is, therefore, important to identify both informal and formal networks to understand the key factors shaping the safety behaviors of construction workers.

The influence of network characteristics on individual behaviors has raised great concern within a wide range of fields. By investigating the social networks of ethnic minority workers, Lyu et al. [29] revealed that the network density and level of reciprocity are important factors distinguishing high and low safety performing crews. Similarly, Zamani et al. [30] figured out the pivotal role of social networks between the safety climate and safety outcomes among excavator crew members in construction projects. Moreover, through the lens of SNA, Abbasianjahromi and Etemadi [31] indicated that there is usually a key worker who affects others because of his status within the construction professional team. Construction projects are labor-intensive. Construction workers form social networks during the construction process. However, few studies reveal how different structural characteristics of construction workers' social networks shape their safety behavior. It is, therefore, imperative to investigate the influencing mechanisms of structure characteristics of social networks on the safety behaviors of construction workers. 
2.3. Safety Communication. Ineffective communication concerning construction safety issues has been identified as one of the important factors in safety-related accidents, as well as the main challenge for practitioners in the construction industry [32]. Alsamadani et al. [33] indicated that the number of safety accidents on construction sites can be effectively reduced by improving the communication efficiency and communication modes among construction workers, such as public discussions, immediate feedback and correction, and the implementation of experience and lesson plans. With the mobility of safety information as the research object, a safety communication network among construction workers can be established and analyzed. Alsamadani et al. [34] revealed that an open communication mode and frequent communication among workers can significantly improve the project safety performance and that the communication modes can include any of multiple forms such as a morning meeting before work, specialized safety meetings, and safety training. In this study, safety communication is defined as the exchange and sharing of safety information among construction workers, and the communication modes include sharing of formal written documents, safety meetings, safety training, and face-to-face and oral communications.

2.4. Node Centrality. The analysis of the node centrality of a social network involves a qualitative evaluation of the power held by various subjects in the network. By occupying different positions in the network structure, subjects will have different abilities to control information and resources, and thus have different effects on self-performance [35]. In social network analysis, there are three main indicators regarding node centrality: degree centrality, closeness centrality, and betweenness centrality. The degree centrality of a directed graph refers to the number of points in direct contact with a node, which can be divided into in-degree and out-degree, from which the relative degree of node centrality can be calculated. In-degree refers to the degree of the effect exerted by other nodes on the nodes in the network, and outdegree refers to the degree of the effect exerted by these nodes on other nodes in the network. The relative degree centrality is the ratio between the degree of all the points and their maximum possible degree in the graph. As with the standardized degree centrality, the relative degree centrality can be used in comparative analyses of the structural characteristics of nodes among networks of different scales. The node centrality can be processed by the UCINET program. Different centrality characteristics are assessed by different calculation formulas. The degree centrality formulas are shown as follows [31]:

$$
\begin{aligned}
& C_{\mathrm{AD}_{i}}=\text { in-degree }+ \text { out-degree, } \\
& C_{\mathrm{RD}_{i}}=\frac{C_{\mathrm{AD}_{i}}}{2 n-2}
\end{aligned}
$$

in which $C_{\mathrm{AD}_{i}}$ refers to the absolute degree centrality of point $i$, and $C_{\mathrm{RD}_{i}}$ refers to the relative degree centrality of point $i$.
The closeness centrality of a node refers to the sum of the geodesic distances between the node and all other nodes in the network, which reflects its proximity to other nodes. The smaller is the closeness centrality, the closer is the relationship with other nodes and the less dependent it is on others to convey and share information. Closeness centrality differs from degree centrality in its consideration of indirect relationships. The formulas for calculating closeness centrality are shown as follows [31]:

$$
\begin{aligned}
C_{\mathrm{AP}_{i}}^{-1} & =\sum_{j=1}^{n} d_{i j}, \\
C_{\mathrm{RP}_{i}}^{-1} & =\frac{C_{\mathrm{AP}_{i}}^{-1}}{n-1},
\end{aligned}
$$

in which $d_{i j}$ refers to the geodesics distance between node $i$ and node $j$, that is, the line number included in the geodesics, $C_{\mathrm{AP}_{i}}^{-1}$ refers to the absolute closeness centrality of node $i$, and $C_{\mathrm{RP}}^{-1}$ refers to the relative closeness centrality of node $i$.

The betweenness centrality of a node refers to the ratio between the total number of geodesics passing the node and connecting two points and the total number of geodesics among these two points, which reflects the extent to which the nodes control the interaction of others, that is, the betweenness. The bigger is the betweenness centrality, the greater is the betweenness. The formulas for calculating the betweenness centrality are shown as follows [31]:

$$
\begin{aligned}
C_{\mathrm{AB}_{i}} & =\sum_{j}^{n} \sum_{k}^{n} b_{j k}(i)=\sum_{j}^{n} \sum_{k}^{n} \frac{g_{j k}(i)}{g_{j k}}, j \neq k \neq i, \text { and } j<k, \\
C_{\mathrm{RB}_{i}} & =\frac{2 C_{\mathrm{AB}_{i}}}{n^{2}-3 n+2}
\end{aligned}
$$

in which $C_{\mathrm{AB}_{i}}$ refers to the absolute betweenness centrality of the node, $C_{\mathrm{RB}_{i}}$ refers to the relative betweenness centrality of the node, $b_{j k}(i)$ refers to the ability of node $I$ to control the interaction of points $j k, g_{j k}$ refers to the number of geodesics between points $j k$, and $g_{j k}(i)$ refers to the number of geodesics passing node $i$ between points $j k$.

\subsection{Hypotheses}

2.5.1. Effect of Social Network Centrality on Safety Behavior. Scholars have conducted a wide-ranging research on the effect of the centrality of social network nodes on employee job performance, but no consensus has been reached regarding its positive or negative effect [36]. In particular, there has been no effective analysis of the effect of node centrality on the safety behavior of construction workers. This paper presents the following research hypothesis based on existing research and current engineering practices in China.

$\mathrm{H1}$ : degree centrality has a positive effect on the safety behavior of construction workers 
Degree centrality is determined by the number of points in direct contact with the nodes in a network [37], and thus reflects the dominant positions of these nodes. The higher is the degree centrality, the greater is the advantage a node has in the possession and control of information, and thus its promotion of improvements in individual performance. In the construction industry, networks formed by individuals include both formal networks based on work relationships and informal networks based on interpersonal relationships. The degree centrality of individuals in formal and informal networks reflects their relative dominance in a group. The higher is the degree centrality, the more knowledge and information are grasped, thus providing conditions necessary for abiding by safety regulations and participating in safety activities. In contrast, the smaller is the degree centrality, the more isolated is the individual and the smaller are the possible effects exerted on and by others, which works against improvements in safety compliance and safety participation. Therefore, sub-hypotheses H1a-H1d are as follows.

H1a: the degree centrality of a formal network has a positive effect on the safety compliance of construction workers

H1b: the degree centrality of an informal network has a positive effect on the safety compliance of construction workers

H1c: the degree centrality of a formal network has a positive effect on the safety participation of construction workers

H1d: the degree centrality of an informal network has a positive effect on the safety participation of construction workers

$\mathrm{H} 2$ : closeness centrality has a negative effect on the safety behavior of construction workers

The difference between closeness centrality and degree centrality lies in their consideration of the indirect relationship among nodes, that is, their closeness to other nodes within the scope of the overall network. The smaller is the closeness centrality, the closer is the node to other nodes, the more central position it has, and the smaller is the possibility that it depends on others for information transfer [38]. In construction activities, the closeness centrality of an individual also reflects his/her closeness to other individuals. The smaller is the closeness centrality of a node in a formal or informal network, the more autonomy it has with respect to safety knowledge, information sharing, and transfer, and the more beneficial is its promotion of activities that comply with safety regulations and the help it offers others to improve safety behavior. Therefore, sub-hypotheses $\mathrm{H} 2 \mathrm{a}-\mathrm{H} 2 \mathrm{~d}$ are as follows:

H2a: the closeness centrality of a formal network has a negative effect on the safety compliance of construction workers

$\mathrm{H} 2 \mathrm{~b}$ : the closeness centrality of an informal network has a negative effect on the safety compliance of construction workers
$\mathrm{H} 2 \mathrm{c}$ : the closeness centrality of a formal network has a negative effect on the safety participation of construction workers

H2d: the closeness centrality of an informal network has a negative effect on the safety participation of construction workers

H3: betweenness centrality has a positive effect on the safety behavior of construction workers

Betweenness centrality mainly considers the intermediary function of the individual in a network, that is, the extent to which information resources or contact with others can be controlled. The greater is the node centrality, the greater is the intermediary function. In construction activities, the greater is the betweenness centrality of an individual in a formal or informal network, the greater is the number of structural holes to which it has access and the greater the power of control it has in the transfer and sharing of safety knowledge or information. As such, betweenness centrality can promote improvement in the levels of safety compliance and safety participation [39]. Therefore, subhypotheses $\mathrm{H} 3 \mathrm{a}-\mathrm{H} 3 \mathrm{~d}$ are as follows:

H3a: the betweenness centrality of a formal network has a positive effect on the safety compliance of construction workers

H3b: the betweenness centrality of an informal network has a positive effect on the safety compliance of construction workers

$\mathrm{H} 3 \mathrm{c}$ : the betweenness centrality of a formal network has a positive effect on the safety participation of construction workers

H3d: the betweenness centrality of an informal network has a positive effect on the safety participation of construction workers

\subsubsection{Effect of Social Network Centrality on Safety} Communication. The social network is a vehicle for the communication of safety information. And the structural characteristics of the social networks where construction workers are embedded in play an important role in shaping the effectiveness of safety communication [34]. Therefore, based on an integration of existing research and current engineering practices in China, the following research hypothesis is proposed:

H4: degree centrality has a positive effect on safety communication among construction workers

As described above, degree centrality reflects the core position of individuals in a network and the extent of their contact with other individuals. An increase in the degree centrality of construction workers implies a greater core position in the network and a greater grasp of safety information and knowledge. Thus, degree centrality will have a relatively significant effect on information network communication and serve to improve the communication level [35]. In construction activities, whether employees are in a formal or informal network, improvement in their degree 
centrality plays an active role in safety communication. Therefore, the following sub-hypotheses $\mathrm{H} 4 \mathrm{a}$ and $\mathrm{H} 4 \mathrm{~b}$ are proposed:

H4a: the degree centrality of a formal network has a positive effect on safety communication

H4b: the degree centrality of an informal network has a positive effect on safety communication

H5: closeness centrality has a negative effect on safety communication among construction workers

Unlike degree centrality, closeness centrality reflects the extent of dependence of an individual on others in terms of information and behavior. The greater is the closeness centrality, the greater is the dependence on others, that is, the greater is the difficulty of obtaining relevant information based on the advantages of their own position. In addition, since there are not many individuals with which the individual is in direct contact, there is a certain restriction on the information disseminated by that individual [38]. In construction activities, the greater is the closeness centrality, the less effective is the communication of safety information. Therefore, the following sub-hypotheses $\mathrm{H} 5 \mathrm{a}$ and $\mathrm{H} 5 \mathrm{~b}$ are proposed:

H5a: the closeness centrality of a formal network has a negative effect on safety communication

$\mathrm{H} 5 \mathrm{~b}$ : the closeness centrality of an informal network has a negative effect on safety communication

H6: betweenness centrality has a positive effect on safety communication among construction workers

Betweenness centrality reflects the number of structural holes to which the individual has access, that is, the capability of having and controlling information. Some researchers have reported that the more access an individual has to structural holes, the greater is his/her effect on information dissemination in the network [39]. In construction activities, the greater is an individual's betweenness centrality, the greater is his/her effect on the efficient communication of safety information, thereby yielding a certain active effect on safety communication. Therefore, the following hypotheses H6a and H6b are proposed:

H6a: the betweenness centrality of a formal network has a positive effect on the safety compliance of construction workers

H6b: the betweenness centrality of an informal network has a positive effect on the safety compliance of construction workers

\subsubsection{Effect of Safety Communication on Safety Behaviors of Construction Workers}

H7: safety communication has a positive effect on the safety behaviors of construction workers

The effect of safety communication on the level of safety behavior exhibited by construction workers has been recognized by most scholars. Kaskutas et al. [40] noted that an increase in the frequency of safety training and safety communication launched by construction supervisors can significantly reduce the occurrence of unsafe behaviors of construction workers and improve their safety awareness and initiative. Compared with the communication between supervisors and construction workers, mutual support and communication among workers can be more effective in improving the level of safety behaviors exhibited by construction workers [41]. Safety communication among construction workers can enable construction workers to become aware of problems promptly, strengthen their awareness of the safety goals of the project team, especially for safety behaviors, and to act to realize the safety goals of the team. Therefore, the following hypotheses H7a and H7b are proposed:

H7a: safety communication has a positive effect on the safety compliance of construction workers

H7b: safety communication has a positive effect on the safety participation of construction workers

2.5.4. Mediation of Safety Communication between Social Network Centrality and the Safety Behavior of Construction Workers. In construction activities, a necessary component of safety communication is the social network established among construction workers. The social network is the carrier and vehicle for the communication of safety information, and the social network established among construction workers through their formal work and social relations can improve the level of safety behavior they exhibit through the communication of safety information. Therefore, based on the above research hypotheses, we hypothesize that safety communication plays a certain mediation role between the centralities of the formal and informal social networks of construction workers and the safety behavior of construction workers. Therefore, the following hypotheses $\mathrm{H} 8$ and $\mathrm{H} 9$ are proposed:

H8: safety communication plays a mediation role between formal network centrality and the safety behavior of construction workers

H9: safety communication plays a mediation role between informal network centrality and the safety behavior of construction workers

Based on the above research hypotheses, Figure 1 shows an overall conceptual model regarding network centralities, safety communication, and safety behavior.

\section{Data and Methods}

3.1. Questionnaire Design. To acquire the data needed for empirical analysis, a questionnaire was designed incorporating the above research variables, including construction workers' social networks, safety communication, and workers' safety behaviors. The questionnaire consists of three parts. The first part addresses basic information about the construction project being investigated, including the project name, city, and project type. The second part 


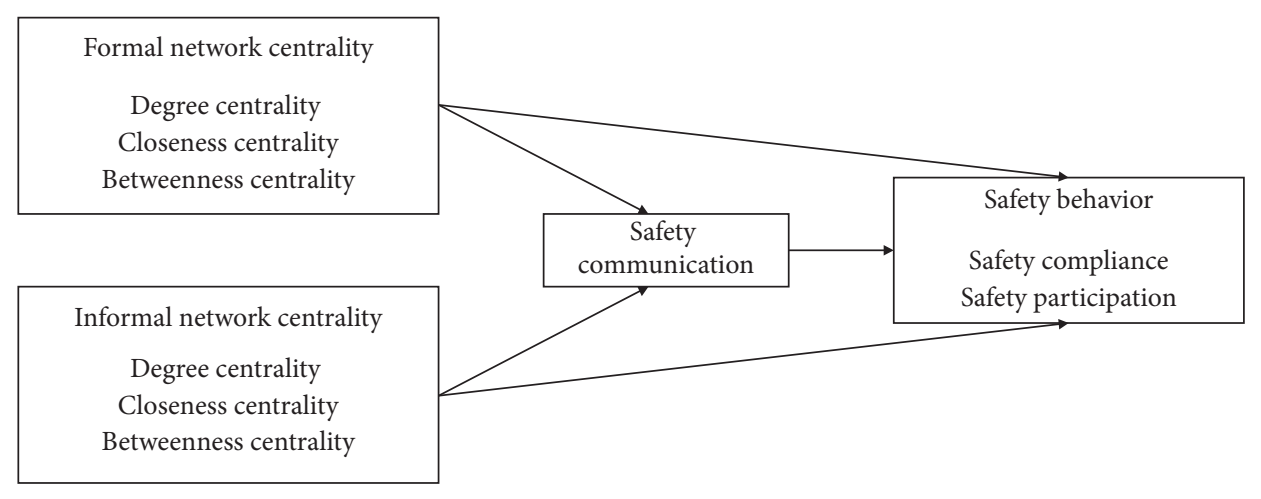

Figure 1: Conceptual model.

contains the main content of the survey of research variables, including measurement of the construction workers' social network, safety communication, and safety behaviors. The third part of the questionnaire asked for personal information from the informant, including gender, age, number of working years, work type, and department.

In the current study, a construction professional team is considered as the unit of network analysis, involving both formal and informal social networks. A construction worker refers to an individual node in the network. By referring to Troster et al. [42] and Reagans et al. [43], we design the questionnaire for holistic network mapping. The social network measurement items are demonstrated in Table 1. The labels (i.e., A, B, C, and D) represent the members' identities of a construction professional team. Formal and informal social networks are measured based on social relationships at work and off the job, respectively.

The measurement of safety communication and safety behaviors adopts a five-point Likert scale, from 1 (strongly disagree) to 5 (strongly agree). Safety communication refers to the communication and exchange of safety knowledge, safety experience, and other safety-related information among construction workers via formal and/or informal ways. Safety behaviors refer to all conducts of construction workers during the construction process that complies with the safety rule. According to Neal et al. [21], safety behaviors can be divided into safety compliance behavior and safety participation behavior. The detailed measurement items of the questionnaire and their sources are shown in Table 2.

3.2. Data Collection and Descriptive Statistics. A suitable sampling method is crucial for ensuring the validity of the collected data in a questionnaire survey. To better capture different types of construction projects within different regions, this paper adopts a probability sampling framework using the stratified technique. More specifically, this study divided samples into different subgroups according to project locations and types and then selected representative cases from each subgroup. The primary data were collected from ten projects under construction across different provinces and municipalities of China (e.g., Shandong, Gansu, Shanxi, Tianjin, and Shanghai). The project types involve railway, road, and housing. Thus, the questionnaire survey covers a wide range of project locations and types, indicating good representativeness. This study selects one construction professional team from each project. Due to the uniqueness of each project, the number of members of each construction professional team is different. Finally, 194 valid questionnaires were completed and returned in total. Table 3 presents the characteristics of the surveyed respondents, and Table 4 presents the distribution of the surveyed projects.

3.3. Calculation Method. Multivariable analysis can be generally divided into correlation and regression analyses. Correlation analysis is used to determine the closeness of relations among variables, with the correlation coefficient being the measurement tool. Regression analysis emphasizes the analysis of the effect of certain variables (independent variables) on specific variables, with the regression coefficient as the measurement tool and correlation analysis serving as the basis for the regression analysis. In this study, the correlation among various variables was determined, followed by an analysis of the effect of the relations between the analysis variables.

Using the acquired data, the centralities of the individual nodes of construction workers were calculated using Ucinet 6.0 software, and a social network model was established for each construction project. Using formulas (1)-(6), the centralities of the formal and informal networks were calculated, including their relative degree centralities $C_{d}$, relative closeness centralities $C_{p}$, and relative betweenness centralities $C_{b}$.

The safety behavior of construction workers as indicated by $S_{C}$ for safety compliance and $S_{P}$ for safety participation, and safety communication is indicated by SC, which represents the average value of various items. The control variables mainly include gender, age, academic background, and working years.

\section{Results and Discussion}

4.1. Correlation Analysis. Given the different nature of variables, the methods used to calculate their correlation coefficients were different. The Pearson simple correlation coefficient was used for continuous variables, the Spearman rank correlation coefficient was used for classified variables, and the Kendall $t$ correlation coefficient was used for 
TABLE 1: The social network measurement items of construction workers.

\begin{tabular}{|c|c|c|c|c|c|c|}
\hline \multirow{2}{*}{ Network type } & \multirow{2}{*}{ Measurement item } & \multicolumn{5}{|c|}{ Worker label } \\
\hline & & A B & C D & $\mathrm{E}$ & $\mathrm{F}$ & G \\
\hline Formal network & $\begin{array}{l}\text { In daily work, who do you often discuss with? } \\
\text { In case of safety risks, who can help you solve the problem first in your mind? } \\
\text { At work, who do you often turn to for advice? }\end{array}$ & & & & & \\
\hline Informal network & $\begin{array}{c}\text { Who do you want to have dinner with most after work? } \\
\text { Who do you often talk with after work? } \\
\text { In daily life, who do you most want to turn to when you have a problem? }\end{array}$ & & & & & \\
\hline
\end{tabular}

TABLE 2: Measurement items of safety communication and safety behavior.

\begin{tabular}{|c|c|c|}
\hline Variable & Items & Sources \\
\hline $\begin{array}{l}\text { Safety } \\
\text { communication }\end{array}$ & $\begin{array}{l}\text { SC1: team members are willing to share safety } \\
\text { information, knowledge, and safety experience } \\
\text { SC2: the communication between the team members is } \\
\text { smooth } \\
\text { SC3: active discussion of safety issues among team } \\
\text { members } \\
\text { SC4: team members actively participate in safety } \\
\text { training } \\
\text { SC5: team members can communicate orally daily } \\
\text { SC6: there are weekly safety meetings between team } \\
\text { members }\end{array}$ & $\begin{array}{c}\text { Peng et al. [44], Downs et al. [45], Alsamadani et al. [34], } \\
\text { and Cigularov et al. [46] }\end{array}$ \\
\hline $\begin{array}{l}\text { Safety compliance } \\
\text { behavior }\end{array}$ & $\begin{array}{l}\text { SCB1: at work, I abide by safety regulations and } \\
\text { operating procedures } \\
\text { SCB2: at work, I use safety helmets, safety belts, and } \\
\text { other labor protection supplies according to regulations } \\
\text { SCB3: I make necessary checks on the safety equipment } \\
\text { or tools I use } \\
\text { SCB4: I can actively cooperate with the command and } \\
\text { arrangement of safety management personnel } \\
\text { SCB5: I also comply with the safety regulations due to } \\
\text { the tight construction schedule and other pressures } \\
\text { SCB6: I do my work only when I am sure that the work } \\
\text { environment is in a highly secure state }\end{array}$ & $\begin{array}{l}\text { Christian et al. [47], DeArmond et al. [48], Neal and } \\
\text { Griffin [49], and Vinodkumar and Bhasi [23] }\end{array}$ \\
\hline $\begin{array}{l}\text { Safety participation } \\
\text { behavior }\end{array}$ & $\begin{array}{l}\text { SPB1: I actively participate in safety meetings } \\
\text { SPB 2: I actively participate in safety education and } \\
\text { training } \\
\text { SPB 3: I volunteered to participate in the emergency } \\
\text { rescue drill } \\
\text { SPB 4: I take part in activities or tasks to improve safety } \\
\text { in the workplace } \\
\text { SPB 5: I am involved in the formulation of the } \\
\text { organization's safety objectives, safety plans, and other } \\
\quad \text { work } \\
\text { SPB 6: I participated in project safety risk assessment } \\
\text { and other work } \\
\text { SPB 7: I help my colleagues when they are in a } \\
\text { dangerous or unfavorable situation } \\
\text { SPB 8: I take the initiative to stop and correct colleagues' } \\
\text { unsafe actions or ideas } \\
\text { SPB 9: I will demonstrate the correct operation to my } \\
\quad \text { colleagues } \\
\text { SPB 10: I exhorted my colleagues to conduct their work } \\
\text { in a safe manner }\end{array}$ & $\begin{array}{l}\text { Christian et al. [47], DeArmond et al. [48], Neal and } \\
\text { Griffin [49], Vinodkumar and Bhasi [23], and Fugas et al. } \\
\text { [50] }\end{array}$ \\
\hline
\end{tabular}

continuous and classified variables. Table 5 shows the results of descriptive and correlation analyses.

From the correlation analyses of the variables in Table 5, it can be seen that the centralities of individual social network nodes in formal and informal networks have a significant positive correlation with safety compliance and safety participation. This indicates that node centrality and the safety behavior of construction workers are highly 
TABLE 3: Descriptive statistics of surveyed respondents $(N=194)$.

\begin{tabular}{|c|c|c|c|}
\hline Variable & Classification & Number & $(\%)$ \\
\hline \multirow{2}{*}{ Gender } & Male & 179 & 92.27 \\
\hline & Female & 15 & 7.73 \\
\hline \multirow{4}{*}{ Age } & $18-30$ years old & 53 & 27.32 \\
\hline & $31-40$ years old & 73 & 37.63 \\
\hline & $41-50$ years old & 55 & 28.35 \\
\hline & Above 51 years old & 13 & 6.70 \\
\hline \multirow{6}{*}{$\begin{array}{l}\text { Academic } \\
\text { background }\end{array}$} & Primary school & 12 & 6.19 \\
\hline & Junior high school & 87 & 44.85 \\
\hline & $\begin{array}{c}\text { Technical secondary } \\
\text { school }\end{array}$ & 22 & 11.34 \\
\hline & Senior high school & 48 & 24.74 \\
\hline & Junior college & 18 & 9.28 \\
\hline & Undergraduate and above & 7 & 3.61 \\
\hline \multirow{5}{*}{ Working years } & 5 years and below & 53 & 27.32 \\
\hline & $6-10$ years & 83 & 42.78 \\
\hline & $11-15$ years & 41 & 21.13 \\
\hline & $16-20$ years & 16 & 8.25 \\
\hline & 21 years and above & 1 & 0.52 \\
\hline \multirow{6}{*}{ Work type } & Woodworker & 24 & 12.37 \\
\hline & Reinforcing ironworker & 64 & 32.99 \\
\hline & Plumber & 56 & 28.86 \\
\hline & Scaffolder & 18 & 9.28 \\
\hline & Measurer & 12 & 6.19 \\
\hline & Others & 20 & 10.31 \\
\hline
\end{tabular}

Note: the digits in brackets () indicate the classification codes of the variables.

correlated, which means further causality analysis is required.

\subsection{Regression Analysis and Discussion}

4.2.1. Effect of Network Centralities on Safety Behavior. The correlation analysis shows a significant correlation between the centralities and safety behaviors of individual social network nodes, but it does not indicate that the network centrality has a direct effect on safety behavior. Therefore, an ordinary least squares (OLS) regression model was applied to perform a multivariable regression analysis, the results of which are shown in Table 6.

In Table 6, after controlling for variables such as gender, age, academic background, and working years, it can be seen that the effect of node centrality on individual safety behavior differs in formal and informal networks. According to the above hypothesis, an explanation and analysis of the effects among various variables are provided.

(1) Effect of Degree Centrality on Safety Behavior. As shown in Table 6, the degree centrality of a formal network has only a positive effect on the safety participation of construction workers $\left(r=0.027^{*}\right)$, whereas that of an informal network has a positive effect on safety compliance $\left(r=0.042^{* *}\right)$ and safety participation $\left(r=0.051^{* *}\right)$. This may be attributed to the fact that construction workers with high degree centrality have more recessive safety knowledge and information [51], a more profound understanding of the harmful consequences of noncompliance with safety behavior, and
TABle 4: Project distributions of surveyed respondents $(N=194)$.

\begin{tabular}{|c|c|c|c|c|}
\hline No. & $\begin{array}{l}\text { Project } \\
\text { type }\end{array}$ & Project location & $\begin{array}{l}\text { Number of } \\
\text { respondents }\end{array}$ & Percentage \\
\hline 1 & Railway & $\begin{array}{l}\text { Gansu, West } \\
\text { China }\end{array}$ & 25 & 12.89 \\
\hline 2 & Road & $\begin{array}{l}\text { Shandong, East } \\
\text { China }\end{array}$ & 24 & 12.37 \\
\hline 3 & $\begin{array}{c}\text { City } \\
\text { complex }\end{array}$ & $\begin{array}{l}\text { Shandong, East } \\
\text { China }\end{array}$ & 23 & 11.85 \\
\hline 4 & Housing & $\begin{array}{l}\text { Tianjin, North } \\
\text { China }\end{array}$ & 22 & 11.34 \\
\hline 5 & Railway & $\begin{array}{l}\text { Shanghai, East } \\
\text { China }\end{array}$ & 20 & 10.31 \\
\hline 6 & Housing & $\begin{array}{l}\text { Tianjin, North } \\
\text { China }\end{array}$ & 20 & 10.31 \\
\hline 7 & Housing & $\begin{array}{l}\text { Guangdong, } \\
\text { South China }\end{array}$ & 18 & 9.28 \\
\hline 8 & Road & $\begin{array}{l}\text { Inner Mongolia, } \\
\text { North China }\end{array}$ & 16 & 8.25 \\
\hline 9 & Housing & $\begin{array}{c}\text { Shanxi, North } \\
\text { China }\end{array}$ & 14 & 7.22 \\
\hline 10 & Housing & $\begin{array}{l}\text { Tianjin, North } \\
\text { China }\end{array}$ & 12 & 6.18 \\
\hline
\end{tabular}

strengthen their compliance behavior accordingly rather than passively intensifying safety compliance by following orders, which is characteristic of a formal network system. Recent research has shown that the social network centrality of individuals shapes their spontaneous altruistic behavior [52]. In this study, concerning safety participation, construction workers with a high degree centrality have more opportunities and conditions in which to unite other personnel to improve safety participation. Therefore, whether in a formal or informal network, degree centrality plays a relatively positive promoting role. Therefore, hypothesis $\mathrm{H} 1$ is partially supported.

(2) Effect of closeness centrality on safety behavior. The regression result shows that the closeness centrality of a formal network has positive effects on safety compliance $\left(r=0.070^{* *}\right)$ and safety participation $\left(r=0.047^{*}\right)$, whereas the closeness centrality of an informal network shows no significant effect on either safety compliance or safety participation. Closeness centrality reflects the intensity with which an individual depends on other individuals [53], and its function in formal and informal networks differs. In formal networks, the more an individual depends on others, the lower is that individual's power, which indicates that instruction or information provided by others is required for that individual to engage in safety activities. Therefore, the greater is the closeness centrality value, the more an individual needs to follow the instructions of others and the better is their safety compliance and the effect others have regarding safety participation activities. In informal networks, the closeness centrality of individuals plays no significant role, which means that individual dependence in the construction process will exert no significant effect on safety behavior. Therefore, hypothesis $\mathrm{H} 2$ is not supported. 


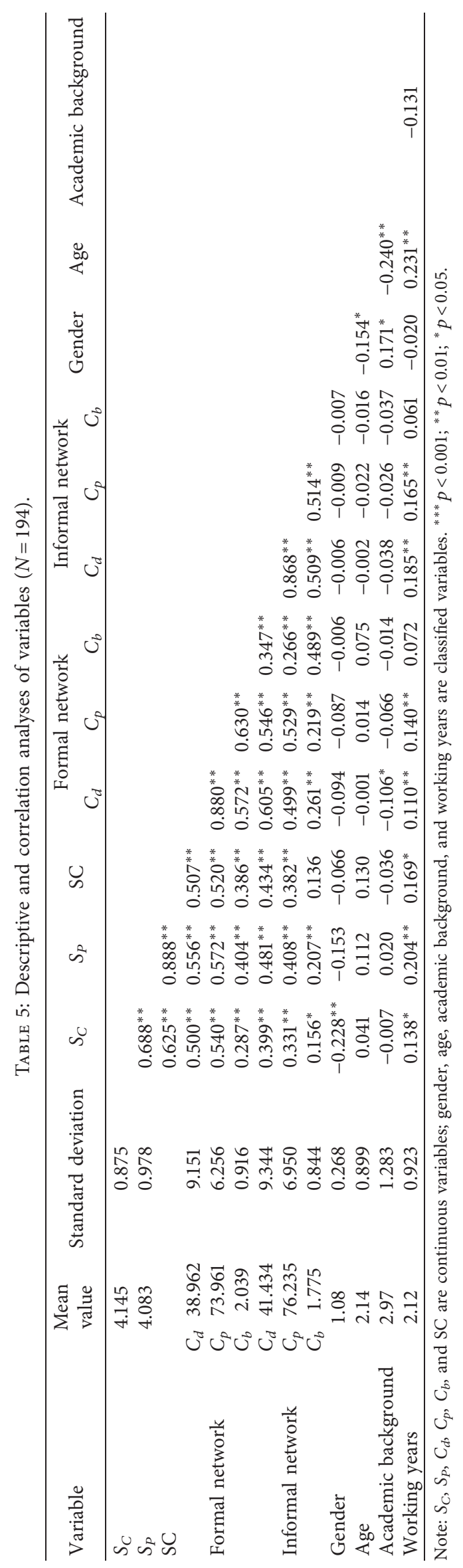


TABLE 6: Regression analysis results of the effect of network centralities on safety behavior.

\begin{tabular}{|c|c|c|c|c|}
\hline \multirow{2}{*}{ Variable } & \multicolumn{2}{|c|}{ Formal network } & \multicolumn{2}{|c|}{ Informal network } \\
\hline & $S_{C}$ & $S_{P}$ & $S_{C}$ & $S_{P}$ \\
\hline Regression intercept & $-0.743(0.999)$ & $-0.937(1.084)$ & 3.343 & $1.901(0.990)$ \\
\hline$C_{d}$ & $0.109(0.012)$ & $0.249(0.013)^{*}$ & $0.447(0.013)^{* *}$ & $0.490(0.014)^{* * *}$ \\
\hline$C_{p}$ & $0.497(0.019)^{* * *}$ & $0.299(0.020)^{*}$ & $-0.016(0.017)$ & $-0.002(0.018)$ \\
\hline$C_{b}$ & $-0.091(0.074)$ & $0.063(0.080)$ & $-0.084(0.080)$ & $-0.058(0.086)$ \\
\hline Gender & $-0.208(0.198)^{* *}$ & $-0.095(0.215)$ & $-0.223(0.218)^{* *}$ & $-0.110(0.235)$ \\
\hline Age & $0.012(0.062)$ & $0.087(0.067)$ & $-0.003(0.067)$ & $0.087(0.073)$ \\
\hline Academic background & $0.097(0.043)$ & $0.122(0.046)^{*}$ & $0.072(0.046)$ & $0.087(0.050)$ \\
\hline Working years & $0.013(0.059)$ & $0.126(0.064)^{*}$ & $0.010(0.066)$ & $0.100(0.071)$ \\
\hline Adjustment $R^{2}$ & 0.322 & 0.362 & 0.182 & 0.242 \\
\hline$F$ value & 14.091 & 16.671 & 7.145 & 9.794 \\
\hline
\end{tabular}

Note: digits in the table are regression coefficients and those in brackets are standard deviations. ${ }^{* * *} p<0.001 ;{ }^{* *} p<0.01 ;{ }^{*} p<0.05$.

(3) Effect of betweenness centrality on safety behavior. The regression results show that the betweenness centrality of a formal network only has a significant positive effect on the safety participation of construction workers $\left(r=0.068^{* *}\right)$, whereas the effect among other variables is insignificant. This is attributed to the fact that the betweenness centrality reflects the number of structural holes to which individuals have access, that is, its intermediary function is rather limited. Freeman [54] noted that "individuals in this position can influence groups by controlling or misinterpreting information." In formal networks, many safety participation activities must be implemented by individuals holding inbetween positions. Therefore, workers with a high betweenness centrality exhibit better safety participation, whereas they do not necessarily exhibit safety compliance. Betweenness centrality in an informal network cannot effectively reflect certain functions, which may be attributed to the fact that construction workers who participated in the survey had no intention of improving their actual safety behavior. Therefore, hypothesis H3 is partially supported.

(4) Effect of the control variables. As shown in Table 6, the gender control variable shows a significant effect on safety compliance. Compared to that of women, the safety compliance of men is relatively better, and this may be attributed to the fact that men have more diversified knowledge and experience in construction activities and some women are temporary construction workers who have relatively limited awareness of safety compliance. The age variable showed no significant effect, whereas academic background and working years both had a significant positive effect on safety participation, which is attributed to the fact that construction workers with higher academic credentials and more working years are more inclined to help others and be aware of the need to ensure the safety of the whole project.

4.2.2. Influence of Network Centrality on Safety Communication. An OLS regression model was utilized to perform a multivariate regression analysis of the influence of safety communication, with a focus on the centrality characteristics of formal and informal networks, the results of which are shown in Table 7.
TABLE 7: Regression results of the effect of network centralities on safety communication.

\begin{tabular}{lcc}
\hline Variable & Formal network & Informal network \\
\hline Regression intercept & $-0.937(1.084)$ & $1.901(0.990)$ \\
$C_{d}$ & $0.249(0.013)^{*}$ & $0.490(0.014)^{* * *}$ \\
$C_{p}$ & $0.299(0.019)^{*}$ & $-0.002(0.018)$ \\
$C_{b}$ & $0.063(0.080)$ & $0.058(0.086)$ \\
Gender & $-0.095(0.215)$ & $-0.110(0.235)$ \\
Age & $0.087(0.067)$ & $0.087(0.073)$ \\
Academic background & $0.122(0.046)^{*}$ & $0.087(0.050)$ \\
Working years & $0.126(0.064)^{*}$ & $0.100(0.071)$ \\
Adjustment $R^{2}$ & 0.362 & 0.242 \\
$F$ value & 16.671 & 9.794 \\
\hline
\end{tabular}

Note: digits in the table are the standardized regression coefficients and those in brackets are standard deviations. ${ }^{* * *} p<0.001 ;{ }^{* *} p<0.01$; ${ }^{*} p<0.05$.

In Table 7, after controlling for variables such as gender, age, academic background, and working years, the influence of node centrality in formal and informal networks was found to differ for the safety communication of construction workers. Regarding the above hypothesis, the influence of various variables is explained and analyzed.

(1) Influence of degree centrality on safety communication. As shown in Table 7, the degree centralities of formal and informal networks have a significant positive effect on safety communication $\left(r=0.249^{*}\right)$ and $\left(r=0.490^{*}\right)$, respectively, which is consistent with the conclusions of previous researchers. This also indicates that the greater are the connections made with others in a construction workers' network, the more the dissemination of safety information and the implementation of safety communication is promoted.

(2) Influence of closeness centrality on safety communication. The results in Table 7 show that the closeness centrality of a formal network has a significant influence on safety communication $\left(r=0.299^{*}\right)$, whereas that of an informal network shows no such influence. In addition, the closeness centrality of a formal network has a positive influence on safety communication, which is exactly opposite to that hypothesized in this article. This may be attributed to the 
relatively high individual closeness centrality in downstream of power in a formal network. In a formal communication mode, safety information communication can be more effectively realized, and the implementation of safety communication will not be hindered by an excessive dependence on others. In an informal network, there is no significant effect of closeness centrality on safety communication due to the absence of any compulsory requirement or arrangements.

(3) Influence of betweenness centrality on safety communication. The results in Table 7 show that the betweenness centralities of formal and informal networks exert no significant influence on safety communication, which may be attributed to the fact that excessive individual betweenness centrality in an organization may lead to the interruption of communication channels in an organization. Despite the many structural holes to which individuals have access, they may not facilitate the dissemination of safety information to others. This also proves that access to an excessive number of structural holes will result in a certain inhibition of information dissemination [55].

4.2.3. Influence of Safety Communication on Safety Behavior. An OLS regression model was also utilized to perform a multivariate regression analysis of the influence of safety communication on safety behavior, the results of which are shown in Table 8.

In Table 8 , it can be seen that safety communication has a significant influence on both the safety compliance and safety participation of construction workers $\left(r=0.684^{* * *}\right)$ and $\left(r=0.875^{* * *}\right)$, respectively, which is consistent with the research findings of most scholars. This shows that in the construction process, the communication and sharing of safety information among construction workers can promote their compliance with safety regulations and participation in activities that improve the level of project safety.

4.2.4. Mediation of Safety Communication. To further explore the influence of safety communication on the safety behavior of construction workers in terms of network centrality, the gradual addition method was used to analyze the mediation effect of safety communication between network centrality and the safety behavior of construction workers [56]. By comparing the changes in the coefficients and model fittings of the relationship of social network centrality with the safety behavior of construction workers before and after safety communication, the mediation effect of safety communication could be determined. The results are shown in Table 9.

A comparison of the results in Tables 6 and 9 shows that after the safety communication variable is considered, the path coefficient between social network centrality and safety behavior with a significant influence relationship and the adjusted $R^{2}$ values are both significantly changed. An explanation is provided below regarding the influence of formal and informal networks on safety behavior.
TABLE 8: Regression results regarding the influence of safety communication on safety behavior.

\begin{tabular}{lcc}
\hline Variable & $S_{C}$ & $S_{P}$ \\
\hline Regression intercept & $2.374(1.084)$ & $0.473(0.229)^{*}$ \\
SC & $0.684(0.048)^{* * *}$ & $0.875(0.035)^{* * *}$ \\
Gender & $-0.148(0.173)^{* *}$ & $-0.083(0.121)^{*}$ \\
Age & $-0.068(0.053)$ & $-0.025(0.037)$ \\
Academic background & $0.008(0.037)$ & $0.060(0.026)$ \\
Working years & $-0.039(0.052)^{*}$ & $0.080(0.036)^{*}$ \\
Adjustment $R^{2}$ & 0.485 & 0.798 \\
$F$ value & 37.406 & 153.34 \\
\hline
\end{tabular}

Note: digits in the table are the standardized regression coefficients and those in brackets are standard deviations. ${ }^{* * *} p<0.001 ;{ }^{* *} p<0.01$; ${ }^{*} p<0.05$.

(1) Mediation effect of safety communication on formal network centrality. For the influence of closeness centrality on safety compliance, from Table 9, it can be seen that after consideration of the safety communication variable, the level of model interpretation is significantly improved, with the adjusted $R^{2}$ value increasing from 0.322 to 0.485 , and although the path coefficient of closeness centrality for safety compliance is reduced from 0.371 to 0.497 , it remains significant. This shows that safety communication plays a partial mediation role between closeness centrality and safety compliance, whereby closeness centrality can promote the safety compliance of construction workers through safety communication. Regarding the influences of degree centrality and closeness centrality on safety participation, the levels of model interpretation also significantly improved, with the adjusted $R^{2}$ value increasing from 0.362 to 0.812 . The path coefficients of degree centrality and closeness centrality for safety participation are insignificant, which indicates that safety communication plays a full mediation role in their relationships and that improving the safety participation of construction workers must be realized through safety communication behavior.

(2) Mediation effect of safety communication on informal network centrality. Regarding the influence of closeness centrality on the safety compliance of construction workers in informal networks, it can be seen from Table 9 that once the safety communication variable is considered, the level of model interpretation shows significant improvement, with the adjusted $R^{2}$ value increasing from 0.182 to 0.431 , and the path coefficient of degree centrality on the safety compliance of construction workers becomes insignificant. This indicates that safety communication plays a full mediation role in both and an important role in terms of the effect of degree centrality in informal networks on safety compliance. Regarding the influence of degree centrality in informal networks on the safety participation of construction workers, when the safety communication variable is considered, the level of model interpretation also significantly improves, with the adjusted $R^{2}$ value increasing from 0.242 to 0.806 . Although the path coefficient of degree centrality on the 
TABLE 9: Mediation effect of safety communication.

\begin{tabular}{lccccc}
\hline Variable & & Formal network & & \multicolumn{2}{c}{ Informal network } \\
& $C_{p} \longrightarrow S_{C}$ & $C_{d} \longrightarrow S_{P}$ & $C_{p} \longrightarrow S_{P}$ & $C_{d} \longrightarrow S_{C}$ & $C_{d} \longrightarrow S_{P}$ \\
\hline Regression intercept & $-0.557(0.871)$ & $-0.595(0.589)$ & $-0.595(0.589)$ & $2.599(0.771)^{* *}$ & $0.656(0.504)$ \\
$C_{d}$ & - & $0.069(0.007)$ & $0.069(0.007)$ & $0.215(0.771)$ & $0.144(0.007)^{*}$ \\
$C_{p}$ & $0.371(0.016)^{* *}$ & - & $0.091(0.011)$ & - & - \\
SC & $0.481(0.059)^{* * *}$ & $0.793(0.040)^{* * *}$ & $0.793(0.040)^{* * *}$ & $0.558(0.058)^{* * *}$ & $0.836(0.038)^{* * *}$ \\
Gender & $-0.198(0.173)^{* * *}$ & $-0.078(0.117)^{*}$ & $-0.078(0.117)^{*}$ & $-0.200(0.182)^{* * *}$ & $-0.075(0.119)^{* * *}$ \\
Age & $-0.045(0.054)$ & $-0.006(0.037)$ & $-0.006(0.037)$ & $-0.071(0.057)$ & $-0.015(0.037)$ \\
Academic background & $0.069(0.037)$ & $0.076(0.025)$ & $0.076(0.025)$ & $0.058(0.039)$ & $0.066(0.025)^{*}$ \\
Working years & $-0.021(0.052)$ & $0.069(0.035)$ & $0.069(0.035)$ & $-0.015(0.055)$ & $0.062(0.036)$ \\
Adjustment $R^{2}$ & 0.485 & 0.812 & 0.812 & 0.431 & 0.806 \\
$F$ value & 23.721 & 105.221 & 105.221 & 19.291 & 101.332 \\
\hline
\end{tabular}

Note: digits in the table are the standardized regression coefficients and those in brackets are standard deviations; ${ }^{* * *} p<0.001 ;{ }^{* *} p<0.01,{ }^{*} p<0.05$.

safety participation of construction workers reduced from 0.490 to 0.144 , it remains significant, which indicates that safety communication plays a partial mediation role in both.

\section{Conclusions}

How to improve the safety behaviors of construction workers to reduce the number of safety accidents has been an ongoing focus of construction engineering management. In previous studies, scholars have explored the effects of individual and/or organizational factors on the safety behaviors of construction workers, but few have investigated the impact of social network structures. This paper adopted a social network approach in which social networks were divided into two types (i.e., formal and informal), and the effects of the node centralities of networks on the safety behaviors of construction workers were investigated, specifically degree, closeness, and betweenness centralities. The results reveal that these three kinds of node centrality in formal networks have a significant positive effect on safety participation, whereas only betweenness centrality has a positive effect on safety compliance. Degree centrality in informal networks was found to have a positive effect on both safety compliance and safety participation. In formal networks, safety communication was found to play a partial mediation role in terms of the effect of closeness centrality on safety compliance and to play full mediation roles in terms of the effects of degree centrality and closeness centrality on safety participation. In informal networks, safety communication plays a full mediation role in terms of the effect of degree centrality on safety compliance and a partial mediation role in terms of the effect of degree centrality on safety participation.

The research results presented in this study provide theoretical support for construction firm administrators to determine approaches and strategies for improving the safety behavior of construction workers based on an understanding of social network structures. The results reveal the importance of the establishment of a formal network structure and the need to improve the node centralities of construction workers by the establishment of general working relationships and improving communication modes to strengthen individual safety behaviors. On the other hand, a good working environment and atmosphere must be established to facilitate improvement in the interpersonal relationships among individuals in groups and to strengthen the function of individual social relation networks to improve safety behavior.

This paper defined research objects within the groups of a small number of engineering projects and the social networks established based on intercept data subject to investigation, and the research results have certain territorial limitations and time constraints. Due to the mobility of personnel and workplaces in the construction process, future research should consider the time factor to enable the analysis of the effect of changes in node centrality towards individual safety behavior and the identification of the dynamic evolution between social networks and safety behaviors to provide better guidance for engineering practice.

The current study is subjected to the following limitations. First, the questionnaire data is cross-sectional. A future study could be performed by collecting the longitudinal data to validate the reliability of observed relationships between variables [57]. Second, this study is rooted in a specific geographic context (i.e., Mainland China). The next stage of research can explore the influence of the structural characteristics of social networks on workers' safety behaviors rooted in different countries or regions and compare the research findings separately. Third, this study focuses on the centrality characteristics of social networks of construction workers. Future research could analyze the effect of other network characteristics (e.g., network density and structure hole) in shaping the workers' safety behaviors.

\section{Data Availability}

The data used to support the findings of this study are available from the corresponding author upon request.

\section{Conflicts of Interest}

The authors declare that they have no conflicts of interest. 


\section{Acknowledgments}

This work was supported by the National Natural Science Foundation of China (71571130 and 71901101), the Fellowship of China Postdoctoral Science Foundation (2020M671134), the Fundamental Research Funds for the Central Universities, China (2662018QD006), and the Opening Foundation of Institute of Rural Revitalization Strategy, Huazhong Agricultural University (2020XCZX06).

\section{References}

[1] L. Kang, C. Wu, X. Liao, and B. Wang, "Safety performance and technology heterogeneity in China's provincial construction industry," Safety Science, vol. 121, pp. 83-92, 2020.

[2] G. Wang, P. Wu, X. Wu, H. Zhang, Q. Guo, and Y. Cai, "Mapping global research on sustainability of megaproject management: a scientometric review," Journal of Cleaner Production, vol. 259, Article ID 120831, 2020.

[3] G. Wang, Q. He, X. Meng, G. Locatelli, T. Yu, and X. Yan, "Exploring the impact of megaproject environmental responsibility on organizational citizenship behaviors for the environment: a social identity perspective," International Journal of Project Management, vol. 35, no. 7, pp. 1402-1414, 2017.

[4] M. Y. Leung, Q. Liang, and P. Olomolaiye, "Impact of job stressors and stress on the safety behavior and accidents of construction workers," Journal of Management in Engineering, vol. 32, no. 1, Article ID 04015019, 2015.

[5] Y. M. Goh and N. F. Binte Sa'adon, "Cognitive factors influencing safety behavior at height: a multimethod exploratory study," Journal of Construction Engineering and Management, vol. 141, no. 6, Article ID 04015003, 2015.

[6] D. Wang, X. Wang, and N. Xia, "How safety-related stress affects workers' safety behavior: the moderating role of psychological capital," Safety Science, vol. 103, pp. 247-259, 2018.

[7] H.-C. Seo, Y.-S. Lee, J.-J. Kim, and N.-Y. Jee, “Analyzing safety behaviors of temporary construction workers using structural equation modeling," Safety Science, vol. 77, pp. 160-168, 2015.

[8] M. Wang, J. Sun, H. Du, and C. Wang, "Relations between safety climate, awareness, and behavior in the Chinese construction industry: a hierarchical linear investigation," $A d-$ vances in Civil Engineering, vol. 2018, Article ID 6580375, 8 pages, 2018

[9] B. Jitwasinkul, B. H. W. Hadikusumo, and A. Q. Memon, “A Bayesian Belief Network model of organizational factors for improving safe work behaviors in Thai construction industry," Safety Science, vol. 82, no. 3, pp. 264-273, 2016.

[10] D. Feldmann and K. H. Welge, "Understanding the causation of construction workers' unsafe behaviors based on system dynamics modeling," Journal of Management in Engineering, vol. 31, no. 6, Article ID 04014099, 2014.

[11] Y. Kim, T. Y. Choi, T. Yan, and K. Dooley, "Structural investigation of supply networks: a social network analysis approach," Journal of Operations Management, vol. 29, no. 3, pp. 194-211, 2011.

[12] X. Wu, H. Yuan, G. Wang, S. Li, and G. Wu, "Impacts of lean construction on safety systems: a system dynamics approach," International Journal of Environmental Research and Public Health, vol. 16, no. 2, Article ID 221, 2019.

[13] J. Lee and S. Kim, "Exploring the role of social networks in affective organizational commitment: network centrality, strength of ties, and structural holes," The American Review of Public Administration, vol. 41, no. 2, pp. 205-223, 2011.

[14] S. Li, X. Wu, X. Wang, and S. Hu, "Relationship between social capital, safety competency and safety behaviors of construction workers," Journal of Construction Engineering and Management, vol. 146, no. 6, Article ID 04020059, 2020.

[15] J. Badham, F. Kee, and R. F. Hunter, "Network structure influence on simulated network interventions for behaviour change," Social Networks, vol. 64, pp. 55-62, 2021.

[16] D. Wang, Y. Guan, and Q. Jia, “"Research on propagation path of construction workers' unsafe behavior based on social network analysis"' Journal of Safety Science and Technology, vol. 14, no. 9, pp. 180-186, 2018, in Chinese.

[17] X. Wu, H. Y. Chong, G. Wang, and S. Li, "The influence of social capitalism on construction safety behaviors: an exploratory megaproject case study," Sustainability, vol. 10, no. 9, Article ID 3098, 2018.

[18] S. Li, M. Fan, and X. Wu, "“Effect of social capital between construction supervisors and workers on workers' safety behavior," Journal of Construction Engineering and Management, vol. 144, no. 4, Article ID 04018014, 2018.

[19] J. P. DePasquale and E. S. Geller, "Critical success factors for behavior-based safety: a study of twenty industry-wide applications," Journal of Safety Research, vol. 30, no. 4, pp. 237-249, 2000.

[20] A. Marchand, M. Simard, M.-C. Carpentier-Roy, and F. Ouellet, "From a unidimensional to a bidimensional concept and measurement of workers' safety behavior," Scandinavian Journal of Work, Environment \& Health, vol. 24, no. 4, pp. 293-299, 1998.

[21] A. Neal, M. A. Griffin, and P. M. Hart, "The impact of organizational climate on safety climate and individual behavior," Safety Science, vol. 34, no. 1-3, pp. 99-109, 2000.

[22] D. A. Hofmann, F. P. Morgeson, and S. J. Gerras, "Climate as a moderator of the relationship between leader-member exchange and content specific citizenship: safety climate as an exemplar," Journal of Applied Psychology, vol. 88, no. 1, pp. 170-178, 2003.

[23] M. N. Vinodkumar and M. Bhasi, "Safety management practices and safety behaviour: assessing the mediating role of safety knowledge and motivation," Accident Analysis \& Prevention, vol. 42, no. 6, pp. 2082-2093, 2010.

[24] B. H. Guo, T. W. Yiu, and V. A. González, "Predicting safety behavior in the construction industry: development and test of an integrative model," Safety Science, vol. 84, no. 1-11, 2016.

[25] J. Scott, "Social network analysis," Sociology, vol. 22, no. 1, pp. 109-127, 1988.

[26] T. R. Zenger, S. G. Lazzarini, and L. Poppo, "Informal and formal organization in new institutional economics," Advances in Strategic Management, vol. 19, no. 1, pp. 277-305, 2002.

[27] J. Böröcz and C. Southworth, “"Who you know” earnings effects of formal and informal social network resources under late state socialism in Hungary, 1986-1987," The Journal of Socio-Economics, vol. 27, no. 3, pp. 401-425, 1998.

[28] B. R. Knost, Formal and Informal Work Group Relationships with Performance: A Moderation Model Using Social Network Analysis, New York, NY, USA, 2012.

[29] S. Lyu, C. K. H. Hon, A. P. C. Chan, A. A. Javed, R. P. Zhang, and F. K. W. Wong, "An exploratory study of safety communication networks of ethnic minority crews in the Hong Kong construction industry," Engineering, Construction and Architectural Management, 2020. 
[30] V. Zamani, S. Y. Banihashemi, and A. Abbasi, "How can communication networks among excavator crew members in construction projects affect the relationship between safety climate and safety outcomes?" Safety Science, vol. 128, Article ID 104737, 2020.

[31] H. Abbasianjahromi and A. Etemadi, "Applying social network analysis to identify the most effective persons according to their potential in causing accidents in construction projects," International Journal of Construction Management, vol. 1, 2019.

[32] R. Y. J. Siew, "Health and safety communication strategy in a Malaysian construction company: a case study," International Journal of Construction Management, vol. 15, no. 4, pp. 310-320, 2015.

[33] R. Alsamadani, M. Hallowell, and A. N. Javernick-Will, "Measuring and modelling safety communication in small work crews in the US using social network analysis," Construction Management and Economics, vol. 31, no. 6, pp. 568-579, 2013.

[34] R. Alsamadani, M. R. Hallowell, A. Javernick-Will, and J. Cabello, "Relationships among language proficiency, communication patterns, and safety performance in small work crews in the United States," Journal of Construction Engineering and Management, vol. 139, no. 9, pp. 1125-1134, 2013.

[35] P. Balkundi and D. A. Harrison, "Ties, leaders, and time in teams: strong inference about network structure's effects on team viability and performance," Academy of Management Journal, vol. 49, no. 1, pp. 49-68, 2006.

[36] R. T. Sparrowe, R. C. Liden, S. J. Wayne, and M. L. Kraimer, "Social networks and the performance of individuals and groups," Academy of Management Journal, vol. 44, no. 2, pp. 316-325, 2001.

[37] A. Mehra, M. Kilduff, and D. J. Brass, "The social networks of high and low self-monitors: implications for workplace performance," Administrative Science Quarterly, vol. 46, no. 1, pp. 121-146, 2001.

[38] R. Cross and J. N. Cummings, "Tie and network correlates of individual performance in knowledge-intensive work," Academy of Management Journal, vol. 47, no. 6, pp. 928-937, 2004.

[39] M. Gargiulo and M. Benassi, "Trapped in your own net? network cohesion, structural holes, and the adaptation of social capital," Organization Science, vol. 11, no. 2, pp. 183-196, 2000.

[40] V. Kaskutas, A. M. Dale, H. Lipscomb, and B. Evanoff, "Fall prevention and safety communication training for foremen: report of a pilot project designed to improve residential construction safety," Journal of Safety Research, vol. 44, pp. 111-118, 2013.

[41] T. W. Casey and A. D. Krauss, "The role of effective error management practices in increasing miners' safety performance," Safety Science, vol. 60, pp. 131-141, 2013.

[42] C. Tröster, A. Mehra, and D. van Knippenberg, "Structuring for team success: the interactive effects of network structure and cultural diversity on team potency and performance," Organizational Behavior and Human Decision Processes, vol. 124, no. 2, pp. 245-255, 2014.

[43] R. Reagans and E. W. Zuckerman, "Networks, diversity, and productivity: the social capital of corporate R\&D teams," Organization Science, vol. 12, no. 4, pp. 502-517, 2001.

[44] G. Peng, J. H. Trienekens, S. W. F. Otma et al., "Inter-organizational communication in food supply chains: Main facets and their interrelationships," in Proceedings of the 2010
Annual World Symposium IFAMA, Boston, MA, USA, June 2010.

[45] C. W. Downs and M. D. Hazen, "A factor analytic study of communication satisfaction," Journal of Business Communication, vol. 14, no. 3, pp. 63-73, 1977.

[46] K. P. Cigularov, P. Y. Chen, and J. Rosecrance, "The effects of error management climate and safety communication on safety: a multi-level study," Accident Analysis \& Prevention, vol. 42, no. 5, pp. 1498-1506, 2010.

[47] M. S. Christian, J. C. Bradley, J. C. Wallace, and M. J. Burke, "Workplace safety: a meta-analysis of the roles of person and situation factors," Journal of Applied Psychology, vol. 94, no. 5, p. 1103, 2009.

[48] S. DeArmond, A. E. Smith, C. L. Wilson, P. Y. Chen, and K. P. Cigularov, "Individual safety performance in the construction industry: development and validation of two short scales," Accident Analysis \& Prevention, vol. 43, no. 3, pp. 948-954, 2011.

[49] A. Neal and M. A. Griffin, "A study of the lagged relationships among safety climate, safety motivation, safety behavior, and accidents at the individual and group levels," Journal of Applied Psychology, vol. 91, no. 4, p. 946, 2006.

[50] C. S. Fugas, S. A. Silva, and J. L. Meliá, "Profiling safety behaviors: exploration of the sociocognitive variables that best discriminate between different behavioral patterns," Risk Analysis, vol. 33, no. 5, pp. 838-850, 2013.

[51] X. Jiang, "Impact of informal network centrality on tacit knowledge sharing in organization," Library and Information Service, vol. 55, no. 16, pp. 111-115, 2011, in Chinese.

[52] X. Chen, Y. Chen, and S. Guo, "Relationship between organizational legitimacy and customer citizenship behavior: a social network perspective," Social Behavior and Personality: An International Journal, vol. 47, no. 1, pp. 1-12, 2019.

[53] F. Yang, G. Chi, G. Wang, S. Tang, Y. Li, and C. Ju, "Untangle the complex stakeholder relationships in rural settlement consolidation in China: a social network approach," Land, vol. 9, no. 7, Article ID 210, 2020.

[54] L. C. Freeman, "Centrality in social networks conceptual clarification," Social Networks, vol. 1, no. 3, pp. 215-239, 1978.

[55] R. S. Burt, Structural Holes: The Social Structure of Competition, Harvard University Press, Cambridge, MA, USA, 2009.

[56] R. M. Baron and D. A. Kenny, "The moderator-mediator variable distinction in social psychological research: conceptual, strategic, and statistical considerations," Journal of Personality and Social Psychology, vol. 51, no. 6, p. 1173, 1986.

[57] G. Wang, Q. He, B. Xia, X. Meng, and P. Wu, "Impact of institutional pressures on organizational citizenship behaviors for the environment: evidence from megaprojects," Journal of Management in Engineering, vol. 34, no. 5, Article ID 04018028, 2018. 